\title{
Adaptive responses along a depth and a latitudinal gradient in the endemic seagrass Posidonia oceanica
}

\author{
Marlene Jahnke ${ }^{1}$ Daniela D'Esposito ${ }^{1}$ Luigi Orrù $^{2} \cdot$ Antonella Lamontanara $^{2} \cdot$ Emanuela Dattolo $^{1}$. \\ Fabio Badalamenti ${ }^{3} \cdot$ Silvia Mazzuca ${ }^{4} \cdot$ Gabriele Procaccini $^{1} \cdot$ Luisa Orsini $^{5}$
}

Received: 5 December 2017 / Revised: 31 May 2018 / Accepted: 5 June 2018 / Published online: 28 June 2018

(c) The Genetics Society 2018

\begin{abstract}
Seagrass meadows provide important ecosystem services and are critical for the survival of the associated invertebrate community. However, they are threatened worldwide by human-driven environmental change. Understanding the seagrasses' potential for adaptation is critical to assess not only their ability to persist under future global change scenarios, but also to assess the persistence of the associated communities. Here we screened a wild population of Posidonia oceanica, an endemic long-lived seagrass in the Mediterranean Sea, for genes that may be target of environmental selection, using an outlier and a genome-wide transcriptome analysis. We identified loci where polymorphism or differential expression was associated with either a latitudinal or a bathymetric gradient, as well as with both gradients in an effort to identify loci associated with temperature and light. We found the candidate genes underlying growth and immunity to be divergent between populations adapted to different latitudes and/or depths, providing evidence for local adaptation. Furthermore, we found evidence of reduced gene flow among populations including adjacent populations. Reduced gene flow, combined with low sexual recombination, small effective population size, and long generation time of $P$. oceanica raises concerns for the long-term persistence of this species, especially in the face of rapid environmental change driven by human activities.
\end{abstract}

These authors contributed equally: Gabriele Procaccini, Luisa Orsini

Electronic supplementary material The online version of this article (https://doi.org/10.1038/s41437-018-0103-0) contains supplementary material, which is available to authorized users.

$\triangle$ Gabriele Procaccini gpro@szn.it

1 Department of Integrative Marine Ecology, Stazione Zoologica Anton Dohrn, Villa Comunale, 80121 Napoli, Italy

2 Consiglio per la ricerca in agricoltura e l'analisi dell'economia agraria, Centro di ricerca per la genomica vegetale, 29017 Fiorenzuola d'Arda, Italy

3 CNR-IAMC, Via G. Da Verrazzano 17, 91014 Castellammare del Golfo, TP, Italy

4 Department of Chemistry and Technology, University of Calabria, Rende, Italy

5 Environmental Genomics Group, School of Biosciences, University of Birmingham, Birmingham B15 2TT, UK

\section{Introduction}

Organisms have historically responded to changes in the environment by migrating, tolerating, or adapting (Hessen et al. 2013). However, human activities exacerbate the environmental changes, imposing shifts in ecological niches that often surpass the adaptive potential of species (HoeghGuldberg et al. 2007) and lead to local extinctions (Cardinale et al. 2012; Smith et al. 2007). Stress imposed by temperature changes has been associated with loss of biodiversity (Both et al. 2006; Corlett and Westcott 2013; Franks et al. 2014; Van Der Wal et al. 2013), with severe consequences on sessile species (Rivetti et al. 2014). Indeed, range reduction of the large majority of benthic marine species has been associated with global warming (Bay and Palumbi 2014; Jueterbock et al. 2016; Sanford and Kelly 2011). However, because of the complex interplay among temperature and other environmental stressors, it remains a challenge to disentangle the impact of temperature stress from one or the other environmental factors.

Here we investigated local adaptation of populations of the seagrass Posidonia oceanica sampled along a latitudinal and a bathymetric gradient, using a genome scan and a 
Fig. 1 Posidonia oceanica sampling. Posidonia oceanica was sampled from six geographic locations in the Mediterranean Sea along a latitudinal transect of $1000 \mathrm{~km}$ at two different depths (5 and $20-25 \mathrm{~m})$

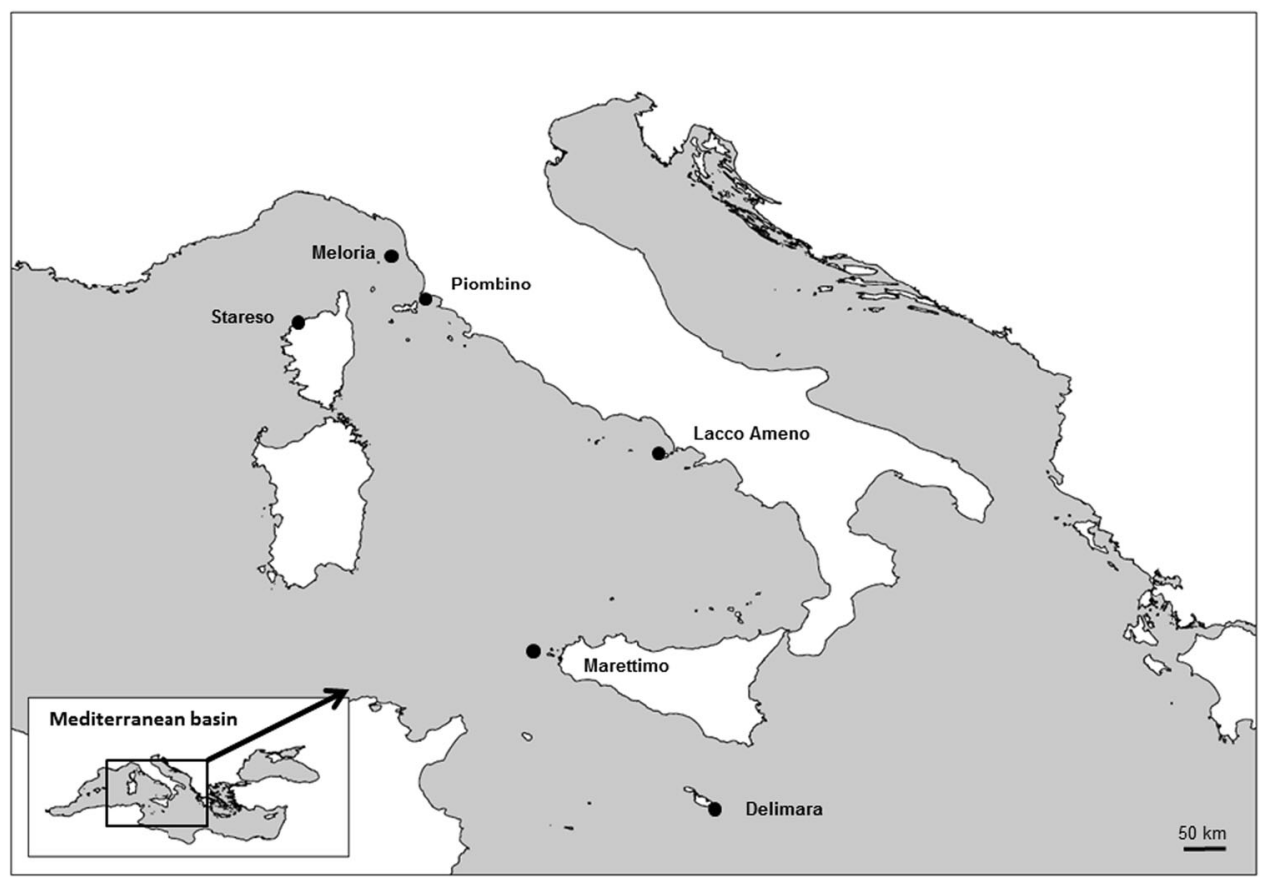

transcriptome analysis. Temperature and light are key environmental factors varying along these gradients; in particular, light is strongly associated with the bathymetric gradient. We hypothesized that a signature of local adaptation shared between the bathymetric and the latitudinal gradient reflects adaptation to temperature, while a signature of local adaptation associated with the bathymetric gradient primarily reflects adaptation to light cues. To test these hypotheses, we mined for outlier loci that are uniquely associated with the bathymetric or latitudinal gradient, as well as for shared outlier loci between the gradients. Furthermore, we performed a genome-wide differential expression analysis to identify candidate genes and gene pathways associated with the bathymetric gradient.

Seagrass meadows are one among the most valuable ecosystems on earth, as they are important providers of ecosystem services and sustain many invertebrate and vertebrate communities (Costanza et al. 1997; Giakoumi et al. 2015). Understanding how seagrasses respond to environmental change is critical not only to assess their ability to persist to future global change, but also to assess the persistence of the associated communities. The seagrass $P$. oceanica (L.) Delile is an endemic long-lived seagrass in the Mediterranean Sea. Individual shoots of this plant survive for decades (Short et al. 2011), and grow via horizontal rhizome elongation (1-10 cm per year; Marbà and Duarte 1998). Single genotypes can persist for millennia via asexual reproduction (Arnaud-Haond et al. 2012; Ruggiero et al. 2002). Flowering via sexual reproduction is extremely heterogeneous at spatial and temporal scales (Diaz-Almela et al. 2006; Jahnke et al. 2015a). Moreover, the establishment success of flowers is low (Balestri and Cinelli 2003; Diaz-Almela et al. 2006). P. oceanica populations in the Mediterranean Sea show pronounced genetic structure (Arnaud-Haond et al. 2007; Serra et al. 2010) with reduced gene flow both across latitudes (Procaccini et al. 2002) and depths (Migliaccio et al. 2005; Procaccini et al. 2001). Low genetic diversity has been observed at regional and global scale (Arnaud-Haond et al. 2007; Serra et al. 2010). Furthermore, low genetic and genotypic diversity have been associated with local or regional extinctions (Jahnke et al. $2015 b$ ). These studies support the predictions of $P$. oceanica functional extinction from the Mediterranean Sea under projected global warming (Jorda et al. 2012).

\section{Materials and methods}

\section{Sampling design}

We collected $P$. oceanica populations from six localities in the Mediterranean Sea along a latitudinal (1000 km, Fig. 1) and a bathymetric gradient. Each locality was sampled at two depths (5 and 20-25 m) (Table S1). Average sea surface temperature (SST) records from the last three decades were provided by Copernicus (SST_MED_SST_L4_REP_OBSERVATIONS_010_021_a_1438858783944) (Nardelli et al. 2013). Using these records, we calculated the average temperature differences among populations (Table $\mathrm{S} 2$ ). Historical records show differences of up to $10^{\circ} \mathrm{C}$ between the two sampled depths, in particular when vertical mixing is prevented by the presence of the summer 
thermocline (Marin-Guirao et al. 2016). This temperature difference is less pronounced in winter. For one of the sampled locations (Stareso, Table S1), the photosynthetic active radiation (PAR) was recorded at the time of sampling $(1 \mathrm{pm})$, and corresponded to 430 and $92 \mu \mathrm{mol} \mathrm{m}^{-2} \mathrm{~s}^{-1}$ at 5 and $20 \mathrm{~m}$, respectively (Procaccini et al. 2017). Comparable differences in irradiance between depths can be expected at the other sampled locations. However, PAR data are not available for all locations.

At each site and from each depth, between 20 and 31 adult leaves of $P$. oceanica were sampled nondestructively (Table S1). The mean distance between the samples at each site ranged between 5 and $8 \mathrm{~m}$ to reduce the chance of collecting identical clones (Arnaud-Haond et al. 2007; Serra et al. 2010). After collection, the leaves were cleaned from epiphytes and stored in silica gel prior to DNA extraction. All samples were genotyped at 23 putatively neutral microsatellite loci, 14 of which were EST-linked (Table S3; Alberto et al. 2003; Arranz et al. 2013; Migliaccio et al. 2005, Procaccini and Waycott 1998).

The Stareso population (Corse, $8^{\circ} 45^{\prime} \mathrm{E}, 42^{\circ} 35^{\prime} \mathrm{N}$, Fig. 1) was previously used to generate a reference transcriptome for P. oceanica (D'Esposito et al. 2016). Here we used the available RNA-Seq data to identify differentially expressed genes between the shallow and deep stands of the same population. As samples were collected at two timepoints within the same day (12 noon and 6.30 p.m.), we also studied plastic response in genome-wide expression in response to light by identifying differential gene expression between the samples collected from the same depth at different timepoints. At the time of sampling, sunrise was at 7.25 a.m. and sunset was at 6.45 p.m.

\section{Population response to environmental change- outlier analysis}

DNA was extracted from 271 samples (ca. $20 \mathrm{mg}$ of dried tissue per sample) collected from the six localities at two depths (Table S1) using the NucleoSpin 96 Plant II kit (Macherey-Nagel), following a modified protocol optimized for a Biomek FX robotic station (Tomasello et al. 2009). Genotyping was performed using an ABI Prism 3730 automated DNA sequencer (Applied Biosystems), following PCR amplification with the following cycling: $95^{\circ} \mathrm{C}$ for $15 \mathrm{~min}, 35$ cycles of $94^{\circ} \mathrm{C}$ for $30 \mathrm{~s}, 60^{\circ} \mathrm{C}$ for $1 \mathrm{~min} 30 \mathrm{~s}$, and $72{ }^{\circ} \mathrm{C}$ for $1 \mathrm{~min}$, with a final extension step of $60^{\circ} \mathrm{C}$ for $30 \mathrm{~min}$. Only samples that were successfully genotyped at $\geq 90 \%$ of the loci (22/24 loci) were used for downstream analyses.

Although the likelihood of sampling the same genotype was low due to our sampling design, we screened for the presence of identical multilocus genotypes (MLGs) using the psex $\left(F_{\mathrm{IS}}\right)$ (the probability that the repeated genotypes originate from distinct sexual reproductive events considering departures from Hardy-Weinberg equilibrium) in GenClone (Arnaud-Haond and Belkhir 2007). When identical MLGs were detected, only one was retained within each site for downstream analyses. Our data-set comprised 237 distinct genotypes (18-22 per population, Table S1).

All genotyped populations were used in an outlier analysis to identify the loci putatively associated with latitudinal and depth gradients. We contrasted pairwise populations at the extreme of the latitudinal gradient. In addition, we contrasted stands of the same population sampled at 5 and $25 \mathrm{~m}$. Prior to this analysis, we performed a population genetic structure analysis, following Orsini et al. (2012). Specifically, we performed an analysis of population genetic differentiation in Arlequin3.5 with 10,000 permutations (Excoffier and Lischer 2010) and a population genetic structure analysis using a discriminant analysis of principal component (DAPC) (Jombart et al. 2010) to identify the number of independent populations present in the dataset. We performed the DAPC implemented in Adegenet (Jombart 2008) in R 3.2.2. (R Development Core Team 2012) using eight principal components, as suggested by the a-score optimization analysis. The analysis of population differentiation and the genetic discrimination identified a northern and a southern population cluster, and identified as independent populations stands of the same populations sampled at different depths (Fig. 2). This separation is also evident from the genetic differentiation analysis (Table S4). Hence, for downstream analysis, we considered populations from the same locality at different depths as independent, and grouped the populations along the latitudinal transect into a northern and a southern group.

To identify the loci putatively linked to environmental factors, we used multiple pairwise population comparisons. This approach has been previously shown to reduce the number of false positives, by showing parallel patterns of locus-specific variation among replicate population comparisons (Orsini et al. 2012). To identify loci associated with the depth gradient, we contrasted the stands of the same population at different depths and a pool of all shallow versus all deep stands (Table S5). To identify loci associated with the latitudinal gradient, we performed pairwise population comparisons separately for the shallow and deep stands. For this analysis, we contrasted three random population pairs from the northern and the southern groups, as well as the pool of northern versus southern populations at the two depths (Table S6). With this approach, we were able to identify putative outlier loci shared between the bathymetric and latitudinal gradients, as well as outlier loci unique to either gradient. The outlier analysis was conducted with Lositan (Antao et al. 2008) and BayeScan (Foll and Gaggiotti 2008). To obtain Lositan results, we run 


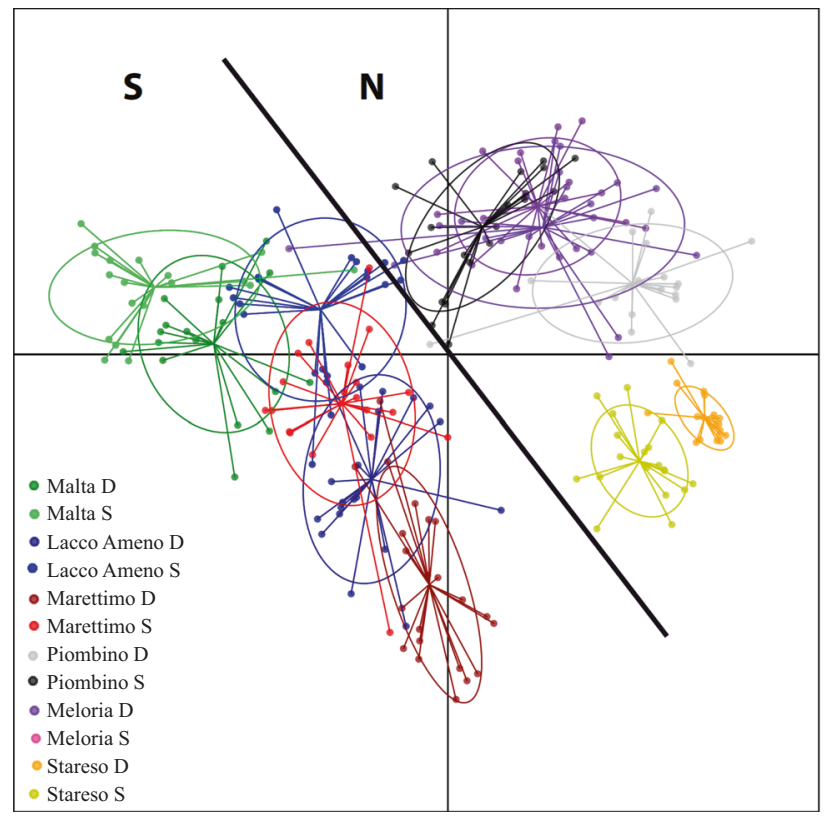

Fig. 2 Population structure analysis. Discriminant analysis of principal component DAPC displaying the total set of 12 Posidonia oceanica populations including shallow and deep stands. The optimal number of principal components found for the analysis was eight. Populations from the same geographic location sampled at different depths are labeled as D (deep) and S (shallow). All populations are uniquely color-coded. N/S identifies the boundary between northern and southern populations

simulations for 50,000 iterations and used a $95 \%$ confidence interval. We performed the BayeScan analysis with default settings and used the provided $\mathrm{R}$ script to identify loci, that show significant deviation from expectations under neutrality, by plotting their posterior distribution. Using a conservative approach to reduce false positives (Orsini et al. 2012), we plotted the number of times loci were detected as outliers in the pairwise population comparisons. To decide on the minimum threshold needed to define an outlier as a locus potentially under selection, we plotted the frequency with which every locus was detected as an outlier in pairwise analyses of population comparisons. Loci falling outside the $95 \%$ boundaries of this frequency distribution were considered as "real" outliers. Loci present only in comparisons from the bathymetric or latitudinal gradient are hereafter referred to as "bathymetric loci" and "latitude loci", respectively. Loci common to the two gradients are referred to as "gradient-shared loci".

\section{Association of neutral and non-neutral genetic variation with the environment}

The outlier analysis allowed us to distinguish neutral from putatively non-neutral loci. These two categories of loci were used in a correlative analysis with temperature and geographic distance. For this correlative analysis, we used the following categories of loci: (1) strictly neutral (not identified as outliers in any of the gradients); (2) gradientshared; (3) latitude loci; and (4) bathymetric loci. On these four categories of loci, we measured the partitioning of molecular variance via AMOVA with GenAlEx 6.5 (Peakall and Smouse 2012), using 1000 permutations. Three hierarchical levels were used: (a) depth (populations at two depths) or latitude (North and South populations, separately for shallow and deep stands); (b) populations within groups, where the groups were either populations at the same depth or at the same latitude; and (c) individuals within populations.

The allele frequencies of loci calculated by shallow and deeps stands, as well as by northern and southern populations are listed in Table S7.

We used ArcGIS $10.1^{\circ}$ (ESRI) to extract the SST values for our sampling locations, and measured geographic distances between sampling locations using the shortest path over the sea without crossing land. We performed a multiple matrix regression with randomization analysis (MMRR) (Wang 2013), using $R$ to identify the correlations between genetic distance (measured as $F_{\mathrm{ST}}$ at both neutral and outlier loci), geographic distance, and temperature (measured as the difference between locations of averaged temperature between 1981 and 2012, the period for which SST is available). MMRR uses a randomized permutation procedure to correct for possible dependency between geographic distance and environmental variables. As compared to a classic partial Mantel test, this method reduces type I errors (Wang 2013). We used 10,000 permutations to test for significant correlations among the standardized matrices of genetic distance, geographic distance, and temperature for shallow populations only, as only superficial SST temperatures were available.

\section{Functional annotation of outlier loci}

The sequences of outlier loci associated with the gradients were used for functional annotations after masking for low complexity regions, which improves gene homology searches. The annotation was done by blasting the sequence of the outlier loci in the NCBI databank and against the reference transcriptome of $P$. oceanica (D'Esposito et al. 2016) using blastx (Altschul et al. 1997), followed by function query in the EMBL-EBI Pfam database (Bateman et al. 2004).

\section{Population response to environmental change- evolutionary and plastic differences in gene expression}

We used RNA-Seq data previously generated to assemble the $P$. oceanica reference transcriptome (D'Esposito et al. 
2016). Transcriptome data were available from the Stareso population. Specifically, two biological replicates, collected at two different times of the day (12 noon and $6.30 \mathrm{pm})$ at two depths (5 and $20 \mathrm{~m}$ depth) were available. PAR at 12 noon was $350 \mu \mathrm{mol} \mathrm{m} \mathrm{m}^{-2} \mathrm{~s}^{-1}$ at $-5 \mathrm{~m}$ and $100 \mu \mathrm{mol} \mathrm{m} \mathrm{m}^{-2} \mathrm{~s}^{-1}$ at $-20 \mathrm{~m}$. PAR values at $6.30 \mathrm{p} . \mathrm{m}$. were $30 \mu \mathrm{mol} \mathrm{m}^{-2} \mathrm{~s}^{-1}$ at $-5 \mathrm{~m}$ and zero at $-20 \mathrm{~m}$, respectively (Procaccini et al. 2017).

We mapped the transcripts onto the reference transcriptome of $P$. oceanica using Bowtie (Langmead et al. 2009) and performed a differential expression analysis between shallow and deep stands, as well as between sampling times at the same depth $(\operatorname{Padj}=0.01)$ with DESeq2 (Love et al. 2014). We calculated the biological coefficent of variation (BCV) on the overall samples using edgeR (McCarthy et al. 2012). For this analysis, only genes with read counts $>1 \mathrm{M}$ in at least two samples were used. The clustering of samples was visualized in an MDS plot using the plotMDS function in edgeR. Genome-wide differential expression profiles were visualized with heatmaps plotted using heatmap. 2 from the R package "gplots". Raw zeta-scores were calculated from the DESeq2 normalized count, using the $\mathrm{R}$ package 'recommenderlab'.

\section{Results}

\section{Population response to environmental change- outlier analysis}

The outlier analysis identified two "gradient-shared loci" (Pooc-PC047G07 and Pooc-50), four "bathymetric loci" (Pooc-PC047G07, Pooc-50, Poc-45, and Pooc-PC003H09, Table S5), and three "latitude loci" (Pooc-PC047G07, Pooc-50, and Pooc-PC045G11, Table S6).

Gradient-shared loci showed similarity to genes with known function. The locus Pooc-50 showed significant similarity to the pEARLI1-like protein 3 (accession Q9SU33.1), a protein associated with membrane lipid transfer in Zostera marina (accession KMZ61949). The locus Pooc-047G07 showed significant similarity to a 50S ribosomal protein L35 (accession PF01632 for structural domain, P23326.1 for gene annotation), one of the large subunits of the ribosome. The frequency of the major allele at the outlier-shared loci was the same in both gradients (Table S7).

The outlier Pooc-PCo45G11, associated with latitude, showed significant similarity to the highly conserved eukaryotic translation initiation factor 5A-1 (accession: P69039.1), which is also a conserved domain (PTZ00328). The bathymetric locus Poc-45 did not show similarity to a gene with known function, whereas the bathymetric locus Pooc-PC003H09 showed high similarity to PR-1, a plant protein associated with pathogens defense mechanisms in plants (accession: P33154.1).

\section{Association of neutral and non-neutral genetic variation with the environment}

The analysis of molecular variance (AMOVA) was performed on four categories of loci: (1) strictly neutral (not identified as outliers in any of the gradients); (2) gradientshared; (3) latitude loci; and (4) bathymetric loci. Overall, the molecular variance showed different patterns for neutral and outlier loci (Table 1). The proportion of molecular variance for all four sets of loci was highest at withinpopulation level (Table 1). The molecular variance at within-group level was significant for neutral loci and comparable between the depth $(22 \%)$ and the latitudinal gradients $(17 \%$ and $19 \%$ - the two depths are analyzed separately, Table 1). For these loci, the among-groups variance was small yet significant (Table 1). The variance of loci associated with latitude was highest at withinpopulation level; for this gradient, $4 \%$ of the variance of outlier loci was associated with group variation (Table 1). All molecular variance in the bathymetric outliers was explained at within-population level (Table 1).

Table 1 Molecular variance

\begin{tabular}{lllll}
\hline & $\begin{array}{l}\text { Hierarchical } \\
\text { level }\end{array}$ & $\begin{array}{l}\text { Among } \\
\text { groups } \\
(\%)\end{array}$ & $\begin{array}{l}\text { Within } \\
\text { groups } \\
(\%)\end{array}$ & $\begin{array}{l}\text { Within } \\
\text { pops. (\%) }\end{array}$ \\
\hline Neutral loci & $\begin{array}{l}\text { Depth } \\
\text { Latitude } \\
\text { shallow }\end{array}$ & 0 & 22 & 78 \\
& Latitude deep & 9 & 17 & 77 \\
Gradient & Depth & 0 & 19 & 72 \\
shared loci & Latitude & 0 & 0 & 100 \\
& shallow & & 100 \\
Latitude loci & Latitude deep & 0 & 0 & 100 \\
& Depth & 0 & 4 & 96 \\
& Latitude & 0 & 4 & 96 \\
& shallow & & & \\
& Latitude deep & 0 & 4 & 96 \\
Bathymetric & Depth & 0 & 1 & 99 \\
& Latitude & 0 & 0 & 100 \\
& shallow & & & 99 \\
& Latitude deep & 0 & 1 &
\end{tabular}

Analysis molecular variance AMOVA for neutral and outlier loci. The variance is partitioned in the following levels: (i) among groups, where groups are either populations along the depth or the latitudinal gradient; (ii) within groups, where the groups are either populations at the same depth or at the same latitude and; (iii) individuals within populations. Significant values $(p<0.001)$ are in italics $(10,000$ permutations). 
Table 2 Correlation among genetic, environmental, and geographic variation

\begin{tabular}{lllll}
\hline & & Intercept & $\begin{array}{l}\text { Geographic } \\
\text { distance }\end{array}$ & Temperature \\
\hline$F_{\text {ST neutral }}$ & Coefficients & -0.157 & 0.116 & 0.541 \\
& $t$-Statistic & -0.570 & 0.467 & 1.809 \\
& $p$-Value & 0.817 & 0.669 & 0.003 \\
$F_{\text {ST gradient }}$ & Coefficients & -0.422 & -0.020 & -0.016 \\
shared loci & $t$-Statistic & -17.164 & -0.891 & -0.597 \\
& $p$-Value & 0.427 & 0.387 & 0.102 \\
$F_{\text {ST latitude }}$ & Coefficients & 0.484 & -0.049 & -0.360 \\
loci & $t$-Statistic & 1.105 & -0.123 & -0.758 \\
& $p$-Value & 0.157 & 0.869 & 0.305 \\
$F_{\text {ST }}$ & Coefficients & -0.290 & -0.452 & 0.498 \\
bathymetric & $t$-Statistic & -0.615 & -1.064 & 0.975 \\
loci & $p$-Value & 0.479 & 0.280 & 0.328 \\
\hline
\end{tabular}

Multiple matrix regression with randomization analysis MMRR showing correlations between geographic distance (measured between sampling locations using the shortest path over the sea without crossing land), genetic distance (measured as $F_{\mathrm{ST}}$ at microsatellite loci), and environmental distance (measured as the difference between locations of averaged temperature between 1981 and 2012). Significant $p$-values are in italics.

The analysis of correlation between genetic distance, temperature, and geographic distance conducted on shallow populations (MMRR) showed that temperature was significantly correlated with neutral genetic variation, but not with genetic variation at the outlier loci (Table 2). This analysis also showed that geographic distance did not correlate with genetic distance among populations neither at neutral nor at outlier loci. Geographic distance correlated significantly with SST ( $p$-value $=0.03$ ).

\section{Population response to environmental change- evolutionary and plastic differences in gene expression}

The genome-wide differential expression analysis was conducted on stands of the Stareso population. This analysis identified a total of 2059 differentially expressed genes between stands, of which 1565 were upregulated and 494 were downregulated (Table S8). Variability in gene expression was high $(\mathrm{BVC}=38 \%)$ among samples. The MDS plot following this analysis revealed a clear separation between shallow and deep stands; moreover, it clustered the samples from same depth (Fig. S1).

A large proportion of the differentially expressed genes identified by the DESeq 2 analysis belonged to five functional categories: transcription factors (TF), metabolic genes, cell wall remodeling, and signaling pathways (Fig. 3, Table S8). The remainder of the differentially expressed genes not falling in these functional categories is listed in
Table S8 and includes a number of uncharacterized proteins. Generally, the two deep samples (taken from the same location but at two different times: 12 noon and $6.30 \mathrm{pm}$ ) showed higher similarity than the two shallow samples in the number of expressed genes and the direction of change in expression (Fig. 3). Differences in genome-wide gene expression between shallow and deep stands were mainly associated with constitutive differential expression of basichelix-loop-helix (bLHL), cell wall genes, and MYB (Fig. 3 and Table S8).

A total of $121 \mathrm{TF}$ were identified in our analysis, falling into four main functional domains, WRKY, MYB, bHLH, and ethylene-responsive genes. MYB and bHLH were largely upregulated in the shallow stand, whereas WRKY TF were largely upregulated in the deep stand (Fig. 3). The TF identified in our analysis have diverse biological functions ranging from disease resistance, abiotic and biotic stress response, senescence, development, differentiation, and metabolism (Table S6). In particular, bHLH is a DNAbinding protein involved in flavonoid biosynthesis (Hichri et al. 2011).

Phenylpropanoids-coding, flavonoid biosynthesis-coding, and lignin biosynthesis-coding genes were highly represented in the differential expression analysis (Fig. 3, Table S8). In the phenylpropanoid pathway, we identified genes coding for cinnamic acid 4-hydroxylase $(\mathrm{C} 4 \mathrm{H})$ and 4 coumarate-coenzyme-A-ligase enzyme (4CL) (Table S8). In the flavonoid biosynthesis pathways, we identified genes coding for chalcone isomerase (CHI) and chalcone synthase (CHS), dihydroflavonol-4-reductase, flavanone-3-hydroxylase, leucoanthocyanidin reductase, and anthocyanidin reductase. In the lignin biosynthesis pathway, we identified innamic-acid-4-hydroxylase, 4-coumarate-CoA-ligase, shikimate-O-hydroxycinnamoyltransferase, caffeoylshikimate esterase, caffeic acid 3-O-methyltransferase, and shikimate O-hydroxycinnamoyltransferase (Table S8).

Most of the transcripts involved in secondary metabolism and cell wall remodeling were upregulated in the shallow population (Fig. 3, Table S8). Among the genes involved in cell wall remodeling, we identified genes coding for xyloglucan endotransglucosylase (XET), expansins, and cellulose synthase. Finally, genes involved in phosphorylation or dephosphorylation were the fourth most abundant category retrieved in our analysis. A large proportion of phosphatases was upregulated in the shallow population (Fig. 3).

\section{Discussion}

We investigated natural populations of $P$. oceanica with the aim of identifying signature of natural selection in response to key environmental factors varying along latitude and depth, such as light and temperature. Our 
Fig. 3 Gene expression analysis. Heatmaps of differentially expressed genes (DEseq $p$-adj $<$ 0.01 ) between the deep and the shallow stands of the Stareso population grouped in functional categories. a basic/helix-loophelix (bHLH), b cell wall, c kinases, d MYB,

e phosphatases, $\mathbf{f}$ secondary metabolism, $\mathbf{g}$ WRKY. S1 and S2-shallow stand sampled at 12 noon and $6.30 \mathrm{pm}$, respectively; D1 and D2-deep stand sampled at 12 noon and 6.30 p.m., respectively. Raw zeta-scores were calculated from the DESeq2 normalized counts

\section{A}

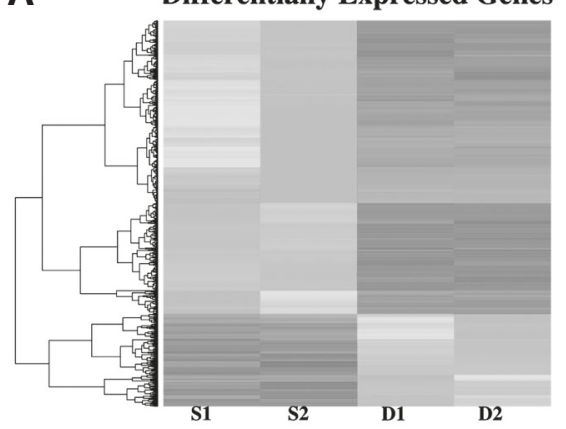

C

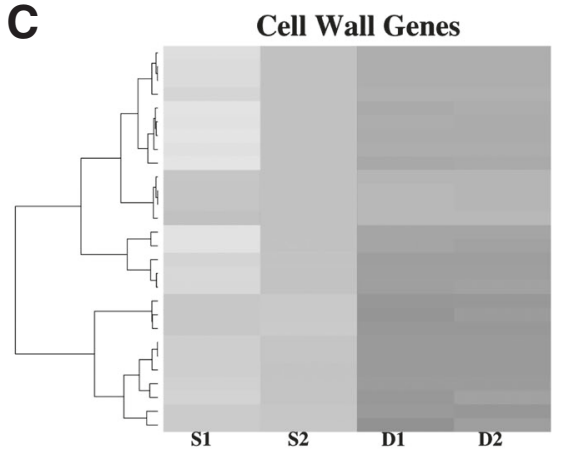

E

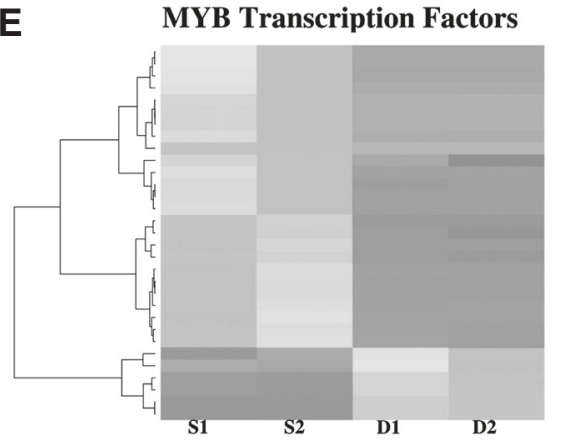

G

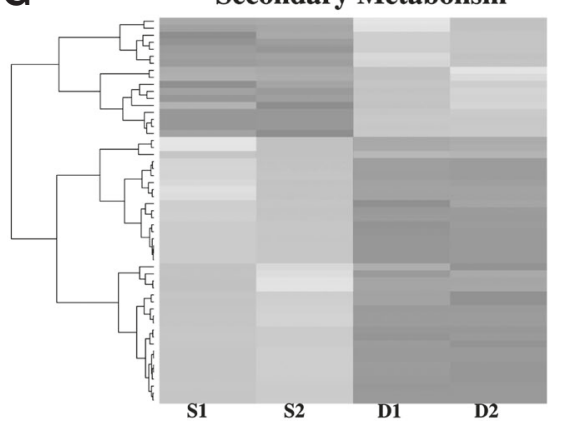

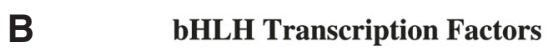

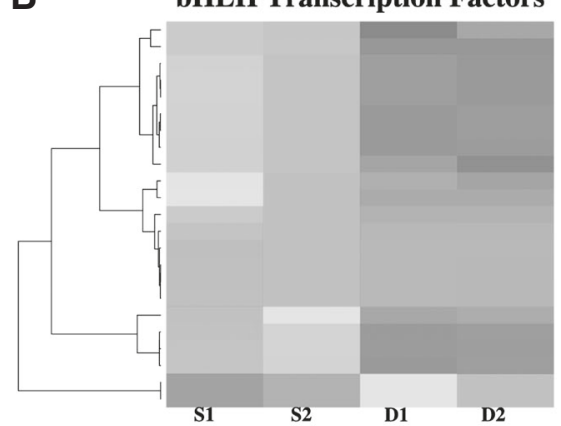

D
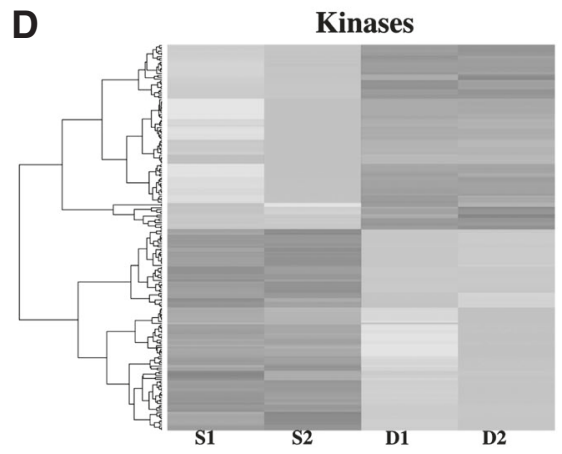

F Phosphatase

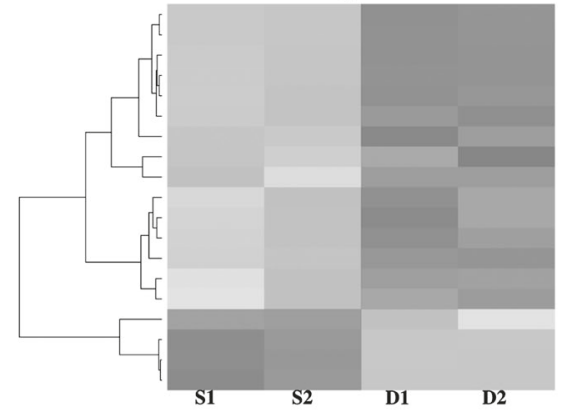

H

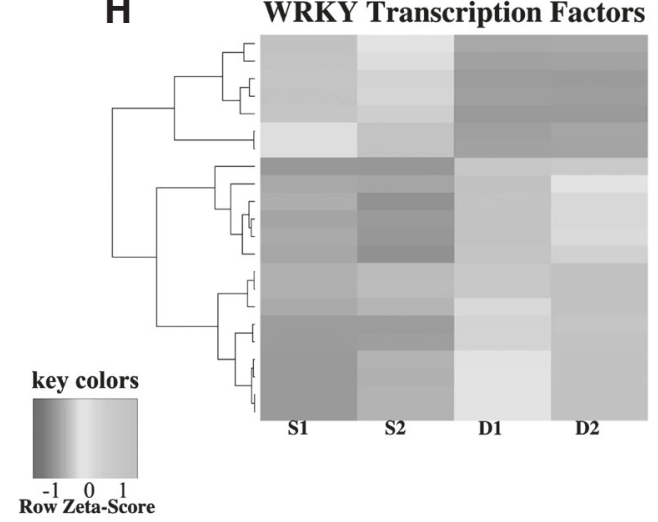

hypothesis testing was that loci shared between the bathymetric and latitudinal gradient were candidates for adaptive responses to temperature, a factor common to the two gradients. Conversely, loci associated with the bathymetric gradient were likely associated with adaptation to different light regimes. 
The candidate loci identified in the outlier analysis and shared between the bathymetric and latitudinal gradient include a ribosomal protein (Pooc-047G07, 50S ribosomal protein L35) and a lipid transfer protein 3 (Pooc-50, pEARLI1-like lipid transfer protein 3), whose functions are potentially associated with both temperature and photoperiod. L35 is a structural constituent of the ribosomes, and is among the cellular proteins differentially regulated under stressful conditions (see review Kosová et al. 2018). In bacteria, L35 is commonly downregulated under thermal stress (e.g., Nevarez et al. 2008). Although mechanisms of stress response differ among taxa, L35 may be potentially involved in stress response in $P$. oceanica. The protein pEARL1-like lipid transfer protein 3 is a member of the proline-rich protein (PRP) family, which has multiple functions in plants: (i) regulation of flowering time and lignin synthesis (Shi et al. 2011); (ii) protection of the plasma membrane and cell wall against low temperature (Zhang and Schläppi 2007); (iii) and resistance to fungal infection. Relevant to our findings is that EARL1 can be activated by temperature and changes in photoperiod (Bubier and Schläppi 2004).

Other candidate loci associated with the bathymetric and latitudinal gradients include the eukaryotic translation initiation factor 5A-1 (Pooc-PCo45G11) and a plant pathogen protein (Pooc-PC003H09). Translation initiation factors have been shown to play a fundamental role in growth and development of plants by regulating cell division, cell growth, and cell death (Feng et al. 2007; Hopkins et al. 2008). Plant pathogenesis-related proteins, such as the PR-1, identified here, are highly expressed in plants after infections and act as an anti-fungal agent (Van Loon et al. 2006). Interestingly, the translation initiation factor 5A-1 is involved in regulation of cellular processes underlying both plant development and programmed cell death (Hopkins et al. 2008), and in response to heat stress (Xu et al. 2011).

The number of loci used in the outlier analysis was small, hence we had limited power in identifying shared-loci between gradients. A genome-wide polymorphism analysis will likely alleviate the limitations of the current study. Overall, the candidate genes identified in the current study regulate central metabolism and cell functions, such as growth and development or are associated with pathogens response. Hence, they do not have a direct link to light or temperature. However, since the link between temperature and metabolism in the context of climate change is wellrecognized (Tewksbury et al. 2008), the candidate genes identified here may be indirectly linked to temperature. For example, cell wall hardening has been suggested to alleviate heat stress in P. oceanica (Marín-Guirao et al. 2017), as well as in other seagrass species (e.g. Z. marina) (Franssen et al. 2014; Jueterbock et al. 2016). Follow-up experiments under controlled laboratory conditions are required to establish a causal association between the putative candidate genes identified here and temperature.

We observed significant divergence in genome-wide gene expression between shallow and deep stands of the Stareso population. Furthermore, we observed a significantly larger divergence between the two shallow than between the two deep samples. Divergence in genome-wide gene expression between shallow and deep stands is likely explained by evolutionary differences in basal gene expression, whereas differences in gene expression between samples collected from the same depth suggests plastic responses to changing irradiance and temperature. Irradiance measured at the Stareso site was markedly different between the two sampling times. Recent studies support the notion that $P$. oceanica living along the bathymetric gradient have differential resilience and are locally adapted to their local environment (Dattolo et al. 2017; Marin-Guirao et al. 2016). Shallow populations of $P$. oceanica show faster and higher induction of heat-response gene, a potential form of local adaptation to higher temperature regimes (MarinGuirao et al. 2016).

Differentially expressed genes between depths were enriched for flavonoid biosynthesis-coding and lignin biosynthesis-coding genes. These are metabolism-linked genes responsible for a wide range of biochemical pathways, providing plants with secondary metabolites (Weisshaar and Jenkins 1998). Also enriched were genes involved in cell wall loosening. These latter genes were generally upregulated in the shallow stand and downregulated in the deep stand, suggesting that bathymetric pressure affects the populations of $P$. oceanica studied here. Finally, the differentially regulated genes between depths included lignin-coding genes, the second most abundant component of plant cell walls, as well as xyloglucan endotransglucosylase (XET), expansins, and cellulose synthase. These genes are commonly associated with cell wall remodeling.

A clear genetic structure was observed both among stands of the same population and among populations. In addition to clear population genetic structure, we observed significant population differentiation $\left(F_{\mathrm{ST}}\right)$, confirming reduced gene flow among populations. The population genetic structure was not explained by geographic distance, as neither neutral nor non-neutral genetic variation were significantly correlated with geographic distance (no isolation by distance, IBD). These findings were in line with previous studies (Arnaud-Haond et al. 2007; Dattolo et al. 2017; Serra et al. 2010). Conversely, neutral genetic variation was significantly correlated with temperature. The patterns of correlation observed here can be explained by a scenario of isolation by colonization (IBC,Orsini et al. 2013), determined by the genetic pattern of early colonization and fueled by low establishment success of 
immigrants. This scenario is supported by observations of limited gene flow among meadows (Arnaud-Haond et al. 2007; Jahnke et al. 2017; Serra et al. 2010) and high levels of clonal reproduction in $P$. oceanica (Arnaud-Haond et al. 2012; Serra et al. 2010). An IBC scenario agrees with the concept of the "founder takes all" put forward by Water et al. (2013). The "founders takes all" scenario suggests that density-dependent processes are likely important in constraining dispersal in the marine environment and play a key role in determining local genetic structure, even in highly connected ecosystems that would otherwise promote panmixia (Waters et al. 2013).

Alternatively, the observed population genetic differentiation observed in our study can be explained by endogenous selection on intrinsic genetic incompatibilities (Bierne et al. 2011). High genetic structure and low gene flow among populations of $P$. oceanica may be indicative of hybrid fitness depression or endogenous selection against migrants (Bierne et al. 2002). Laboratory crosses and fitness analysis across multiple generations is required to validate this hypothesis.

\section{Conclusions}

The candidate genes associated with depth and/or latitude underpin central metabolic, cell remodeling, and immunoregulation functions. Given the demonstrated link between metabolism and temperature, most of the assessed genes may be indirectly associated with temperature response. Moreover, some of the candidate genes associated with both gradients have been previously linked to temperature and/or light.

The analysis of genome-wide differential gene expression clearly identified divergence in basal expression of five protein functional categories. This divergence is likely explained by adaptation to the local environment. Evidence for reduced gene flow among populations and among stands of the same population at different depths combined with low sexual recombination, small effective population size, and long generation time of $P$. oceanica pose concerns for the long-term persistence of this species, especially in the face of rapid environmental change driven by human activities. These concerns are supported by a recent metaanalysis suggesting that $P$. oceanica meadows with low genetic and genotypic diversity are unable to persist in highly impacted areas (Jahnke et al. 2015b).

\section{Data archiving}

Microsatellites genotypes available from the Dryad Digital Repository: https://doi.org/10.5061/dryad.44s3k14. The reference transcriptome of $P$. oceanica is available at NCBI (Accession number: GEMD01000000). The data generated in this manuscript are available at the NCBI Sequence Read Archive (SRA) under the accession numbers SRR3289754, SRR3289740, SRR3289755, and SRR3289704.

Acknowledgements We thank the ESF COST Action (ES0906) Seagrass Productivity: from Genes to Ecosystem Management for the funds provided for the sampling campaign. This research was partially supported by the MIUR Italian Flagship project RITMARE, by Università della Calabria research funds. DDE and MJ were supported by a SZN Ph.D. fellowship via the Open University.

Authors' contributions: MJ performed the population genetic analyses and wrote the first manuscript draft. DDE and ED performed the genotyping. DDE also performed RNA extraction for the transcriptomic analysis. LO (Luigi Orru') and AL performed the DE analysis and the functional gene annotation. GP and FB conceived the sampling strategy along the latitudinal gradient. FB coordinated and performed the sampling of two populations. SM and GP conceived the transcriptomic work. GP conceived the study and coordinated the experimental work. LO (Luisa Orsini) coordinated data analysis and manuscript writing. All authors contributed to manuscript editing.

\section{Compliance with ethical standards}

Conflict of interest The authors declare that they have no conflict of interest.

\section{References}

Alberto F, Correia L, Arnaud-Haond S, Billot C, Duarte CM, Serrão EA (2003) New microsatellite markers for the endemic Mediterranean seagrass Posidonia oceanica. Mol Ecol Notes 3 (2):253-255

Altschul SF, Madden TL, Schäffer AA, Zhang J, Zhang Z, Miller W et al. (1997) Gapped BLAST and PSI-BLAST: a new generation of protein database search programs. Nucleic Acids Res 25 (17):3389-3402

Antao T, Lopes A, Lopes R, Beja-Pereira A, Luikart G (2008) LOSITAN: a workbench to detect molecular adaptation based on a Fst-outlier method. BMC Bioinform 9(1):323

Arnaud-Haond S, Belkhir K (2007) genclone: a computer program to analyse genotypic data, test for clonality and describe spatial clonal organization. Mol Ecol Notes 7(1):15-17

Arnaud-Haond S, Duarte CM, Diaz-Almela E, Marbà N, Sintes T, Serrão EA (2012) Implications of extreme life span in clonal organisms: millenary clones in meadows of the threatened seagrass Posidonia oceanica. PLoS ONE 7(2):e30454

Arnaud-Haond S, Migliaccio M, Diaz-Almela E, Teixeira S, van de Vliet MS, Alberto F et al. (2007) Vicariance patterns in the Mediterranean Sea: east-west cleavage and low dispersal in the endemic seagrass Posidonia oceanica. J Biogeogr 34(6):963-976

Arranz SE, Avarre J-C, Balasundaram C, Bouza C, Calcaterra NB, Cezilly F et al. (2013) Permanent genetic resources added to molecular ecology resources database 1 December 2012-31 January 2013. Mol Ecol Resour 13(3):546-549

Balestri E, Cinelli F (2003) Sexual reproductive success in Posidonia oceanica. Aquat Bot 75(1):21-32

Bateman A, Coin L, Durbin R, Finn RD, Hollich V, Griffiths-Jones S et al. (2004) The Pfam protein families database. Nucleic Acids Res 32(Suppl 1):D138-D141 
Bay RA, Palumbi SR (2014) Multilocus adaptation associated with heat resistance in reef-building corals. Curr Biol 24 (24):2952-2956

Bierne N, Patrice D, Boudry P, Bonhomme F (2002) Assortative fertilization and selection at larval stage in the Mussels Mytilus edulis and M. galloprovincialis. Evolution 2:292-298

Bierne N, Welch J, Loire E, Bonhomme F, David P (2011) The coupling hypothesis: why genome scans may fail to map local adaptation genes. Mol Ecol 20:2044-2072

Both C, Bouwhuis S, Lessells C, Visser ME (2006) Climate change and population declines in a long-distance migratory bird. Nature 441(7089):81-83

Bubier J, Schläppi M (2004) Cold induction of EARLI1 a putative Arabidopsis lipid transfer protein, is light and calcium dependent. Plant Cell Environ 27:929-936

Cardinale BJ, Duffy JE, Gonzalez A, Hooper DU, Perrings C, Venail P et al. (2012) Biodiversity loss and its impact on humanity. Nature 486(7401):59-67

Corlett RT, Westcott DA (2013) Will plant movements keep up with climate change? Trends Ecol Evol 28(8):482-488

Costanza R, d'Arge R, De Groot R, Farber S, Grasso M, Hannon B et al. (1997) The value of the world's ecosystem services and natural capital. Nature 387(6630):253-260

Dattolo E, Marïn-Guirao L, Ruiz JM, Procaccini G (2017) Long-term acclimation to reciprocal light conditions suggests depth-related selection in the marine foundation species Posidonia oceanica. Ecol Evol 7:1148-1164

D'Esposito D, Orrù L, Dattolo E, Bernardo L, Lamontara A, Orsini L et al. (2016) Transcriptome characterisation and simple sequence repeat marker discovery in the seagrass Posidonia oceanica. Sci Data 3:160115

Diaz-Almela E, Marbà N, Alvarez E, Balestri E, Ruiz-Fernandez JM, Duarte CM (2006) Patterns of seagrass (Posidonia oceanica) flowering in the Western Mediterranean. Mar Biol 148 (4):723-742

Excoffier L, Lischer HE (2010) Arlequin suite ver 3.5: a new series of programs to perform population genetics analyses under Linux and Windows. Mol Ecol Resour 10(3):564-567

Feng H, Chen Q, Feng J, Zhang J, Yang X, Zuo J (2007) Functional characterization of the Arabidopsis eukaryotic translation initiation factor 5A-2 that plays a crucial role in plant growth and development by regulating cell division, cell growth, and cell death. Plant Physiol 144(3):1531-1545

Foll M, Gaggiotti O (2008) A genome-scan method to identify selected loci appropriate for both dominant and codominant markers: a Bayesian perspective. Genetics 180(2):977-993

Franks SJ, Weber JJ, Aitken SN (2014) Evolutionary and plastic responses to climate change in terrestrial plant populations. Evol Appl 7(1):123-139

Franssen SU, Gu J, Winters G, Huylmans A-K, Wienpahl I, Sparwel $M$ et al (2014) Genome-wide transcriptomic responses of the seagrasses Zostera marina and Nanozostera noltii under a simulated heatwave confirm functional types. Mar Genom 15:65-73

Giakoumi S,Halpern BS,Michel LN,Gobert S,Sini M,Boudouresque CF, et al.(2015) Towards a framework for assessment and management of cumulative human impacts on marine food webs Conserv Biol 29(4):1228-1234

Hessen DO, Daufresne M, Leinaas HP (2013) Temperature-size relations from the cellular-genomic perspective. Biol Rev 88 (2):476-489

Hichri I,Barrieu F, Bogs J, Kappel C, Delrot S, Lauvergeat V (2011) Recent advances in the transcriptional regulation of the flavonoid biosynthetic pathway. Journal of Experimental Botany 62 (8):2465-2483
Hoegh-Guldberg O, Mumby PJ, Hooten AJ, Steneck RS, Greenfield P, Gomez E et al. (2007) Coral reefs under rapid climate change and ocean acidification. Science 318(5857):1737-1742

Hopkins MT, Lampi Y, Wang T-W, Liu Z, Thompson JE (2008) Eukaryotic translation initiation factor $5 \mathrm{~A}$ is involved in pathogen-induced cell death and development of disease symptoms in Arabidopsis. Plant Physiol 148(1):479-489

Jahnke M, Alcoverro T, Lavery PS, McMahon KM, Procaccini G (2015a) Should we sync? Seascape-level genetic and ecological factors determine seagrass flowering patterns. J Ecol 103 (6):1464-1474

Jahnke M, Casagrandi R, Melià P, Schiavina M, Schultz S, Zane L et al. (2017) Potential and realized connectivity of the seagrass Posidonia oceanica and their implication for conservation. Divers Distrib 23:1423-1424

Jahnke M, Olsen JL, Procaccini G (2015b) A meta-analysis reveals a positive correlation between genetic diversity metrics and environmental status in the long-lived seagrass Posidonia oceanica. Mol Ecol 24(10):2336-2348

Jombart T (2008) adegenet: a R package for the multivariate analysis of genetic markers. Bioinformatics 24(11):1403-1405

Jombart T, Devillard S, Balloux F (2010) Discriminant analysis of principal components: a new method for the analysis of genetically structured populations. BMC Genet 11(1):94

Jorda G, Marbà N, Duarte CM (2012) Mediterranean seagrass vulnerable to regional climate warming. Nat Clim Change 2 (11):821-824

Jueterbock A, Franssen SU, Bergmann N, Gu J, Coyer JA, Reusch TB et al. (2016) Phylogeographic differentiation versus transcriptomic adaptation to warm temperatures in Zostera marina, a globally important seagrass. Mol Ecol 25(21):5396-5411

Kosová K, Vítámvás P, Urban MO, Prášil IT, Renaut J (2018) Plant abiotic stress proteomics: the major factors determining alterations in cellular proteome. Front Plant Science 9:122

Langmead B, Trapnell C, Pop M, Salzberg SL (2009) Ultrafast and memory-efficient alignment of short DNA sequences to the human genome. Genome Biol 10(3):1

Love MI, Huber W, Anders S (2014) Moderated estimation of fold change and dispersion for RNA-seq data with DESeq2. Genome Biol 15(12):1-21

Marbà N, Duarte CM (1998) Rhizome elongation and seagrass clonal growth. Mar Ecol Prog Ser 174:269-280

Marín-Guirao L, Entrambasaguas L, Dattolo E, Ruiz JM, Procaccini G (2017) Molecular mechanisms behind the physiological resistance to intense transient warming in an iconic marine plant. Front Plant Sci 8:1142

Marin-Guirao L, Ruiz JM, Dattolo E, Garcia-Munoz R, Procaccini G (2016) Physiological and molecular evidence of differential shortterm heat tolerance in Mediterranean seagrasses. Sci Rep 6:28615

McCarthy JD, Yunshun C, Smyth KG (2012) Differential expression analysis of multifactor RNA-Seq experiments with respect to biological variation. Nucleic Acids Res 40:4288-4297

Migliaccio M, De Martino F, Silvestre F, Procaccini G (2005) Meadow-scale genetic structure in Posidonia oceanica. Mar Ecol Prog Ser 304:55-65

Nardelli BB, Tronconi C, Pisano A, Santoleri R (2013) High and ultrahigh resolution processing of satellite sea surface temperature data over Southern European Seas in the framework of MyOcean project. Remote Sens Environ 129:1-16

Nevarez L, Vasseur V, Le Drean G, Tanguy a, Guisle-Marsollier I, Houlgatte R et al. (2008) Isolation and analysis of differentially expressed genes in Penicillium glabrum subjected to thermal stress. Microbiology 154:3752-3765

Orsini L, Spanier KI, De Meester L (2012) Genomic signature of natural and anthropogenic stress in wild populations of the 
waterflea Daphnia magna: validation in space, time and experimental evolution. Mol Ecol 21(9):2160-2175

Orsini L, Vanoverbeke J, Swillen I, Mergeay J, Meester L (2013) Drivers of population genetic differentiation in the wild: isolation by dispersal limitation, isolation by adaptation and isolation by colonization. Mol Ecol 22(24):5983-5999

Peakall R, Smouse PE (2012) GenAlEx 6.5: genetic analysis in Excel. Population genetic software for teaching and research-an update. Bioinformatics 28(19):2537-2539

Procaccini G, Orsini L, Ruggiero MV, Scardi M (2001) Spatial patterns of genetic diversity in Posidonia oceanica, an endemic Mediterranean seagrass. Mol Ecol 10(6):1413-1421

Procaccini G, Ruggiero MV, Orsini L (2002) Genetic structure and distribution of microsatellite population genetic diversity in Posidonia oceanica in the Mediterranean basin. Bull Mar Sci 71 (3):1291-1297

Procaccini G, Ruocco M, Marín-Guirao L, Dattolo E, Brunet C, D'Esposito D et al. (2017) Depth-specific fluctuations of gene expression and protein abundance modulate the photophysiology in the seagrass Posidonia oceanica. Sci Rep 7:42890

Procaccini G, Waycott M (1998) Brief communication. Microsatellite loci identified in the seagrass Posidonia oceanica (L.) Delile. J Hered 89(6):562-568

R Development Core Team (2012). R: A language and environment for statistical computing. R Foundation for Statistical Computing, Vienna, Austria

Rivetti I, Fraschetti S, Lionello P, Zambianchi E, Boero F (2014) Global warming and mass mortalities of benthic invertebrates in the Mediterranean Sea. PLoS ONE 9(12):e115655

Ruggiero M, Turk R, Procaccini G (2002) Genetic identity and homozygosity in North-Adriatic populations of Posidonia oceanica: An ancient, post-glacial clone? Conserv Genet 3(1):69-72

Sanford E, Kelly MW (2011) Local adaptation in marine invertebrates. Annu Rev Mar Sci 3:509-535

Serra IA, Innocenti AM, Di Maida G, Calvo S, Migliaccio M, Zambianchi E et al. (2010) Genetic structure in the Mediterranean seagrass Posidonia oceanica: disentangling past vicariance events from contemporary patterns of gene flow. Mol Ecol 19 (3):557-568
Shi Y, Zhang X, Xu ZY, Li L, Zhang C, Schläppi M et al. (2011) Influence of EARLI1-like genes on flowering time and lignin synthesis of Arabidopsis thaliana. Plant Biol 13:731-739

Short FT, Polidoro B, Livingstone SR, Carpenter KE, Bandeira S, Bujang JS et al. (2011) Extinction risk assessment of the world's seagrass species. Biol Conserv 144(7):1961-1971

Smith DM, Cusack S, Colman AW, Folland CK, Harris GR, Murphy JM (2007) Improved surface temperature prediction for the coming decade from a global climate model. Science 317 (5839):796-799

Tewksbury JJ, Huey RB, Deutsch CA (2008) Putting the heat on tropical animals. Sci-N Y Then Wash 320(5881):1296

Tomasello A, Di Maida G, Calvo S, Pirrotta M, Borra M, Procaccini G (2009) Seagrass meadows at the extreme of environmental tolerance: the case of Posidonia oceanica in a semi-enclosed coastal lagoon. Mar Ecol 30(3):288-300

Van Der Wal J, Murphy HT, Kutt AS, Perkins GC, Bateman BL, Perry JJ et al. (2013) Focus on poleward shifts in species' distribution underestimates the fingerprint of climate change. Nat Clim Change 3(3):239-243

Van Loon LC, Rep M, Pieterse C (2006) Significance of inducible defense-related proteins in infected plants. Annu Rev Phytopathol 44:135-162

Wang IJ (2013) Examining the full effects of landscape heterogeneity on spatial genetic variation: a multiple matrix regression approach for quantifying geographic and ecological isolation. Evolution 67 (12):3403-3411

Waters JM, Fraser CI, Hewitt GM (2013) Founder takes all: densitydependent processes structure biodiversity. Trends Ecol Evol 28 (2):78-85

Weisshaar B, Jenkins GI (1998) Phenylpropanoid biosynthesis and its regulation. Curr Opin Plant Biol 1(3):251-257

Xu J, Zhang B, Jiang C, Ming F (2011) RcelF5A, encoding an eukaryotic translation initiation factor $5 \mathrm{~A}$ in Rosa chinensis, can enhance thermotolerance, oxidative and osmotic stress resistance of Arabidopsis thaliana. Plant Mol Biol 75:167-178

Zhang Y, Schläppi M (2007) Cold responsive EARLI1 type HyPRPs improve freezing survival of yeast cells and form higher order complexes in plants. Planta 227:233-243 